\title{
COMMENTARY
}

\section{Red cell transfusion triggers in critically ill patients: time for some new TRICCs?}

\author{
Timothy S Walsh* \\ See related research by Sakr et al., http://ccforum.com/content/14/3/R92
}

\begin{abstract}
Current evidence suggests that critically ill patients tolerate anaemia well and that blood transfusions may increase the risk of adverse outcomes. Dr Sakr and colleagues present a contradictory analysis of a surgical ICU cohort, finding an association between blood transfusions and lower hospital mortality after adjustment for a range of potential confounders. Analyses of this kind are interesting and provocative, but are limited by residual confounding and bias by indication. The data emphasise the need for additional high quality trials of transfusion practice in critical care.
\end{abstract}

Dr Sakr and colleagues [1] report a single centre cohort study evaluating the relationship between anaemia, blood transfusions and mortality in patients admitted to a surgical ICU. The authors report some findings that are not new or surprising, namely that anaemia is associated with adverse patient outcomes. However, when they performed multivariate analyses with adjustment for potential confounders to the blood transfusion/patient outcomes relationship they found that transfusions were associated with lower patient mortality, especially among older sicker patients. At face value this contradicts the majority of previous cohort studies [2] and the only large randomised trial of different transfusion triggers in critically ill patients (the Canadian Critical Care Trials Group's 'Transfusion requirements in critical care' (TRICC) trial) [3]. The authors' findings raise a number of questions, including: does this association indicate cause and effect'? Are the findings of the TRICC trial generalisable to intensive care patients today? And, perhaps most importantly, should we use blood more liberally in critically ill patients than the TRICC trial and our current guidelines suggest?

*Correspondence: twalsh@staffmail.ed.ac.uk

Anaesthetics, Critical Care and Pain Medicine, Royal Infirmary of Edinburgh, Little France Crescent, Edinburgh EH16 2SA, UK

\section{Does this association indicate 'cause and effect'?}

Although it is possible to perform complex statistical adjustments for potential confounders in cohort studies to try to clarify the true relationship between a variable or intervention of interest and an outcome, this is notoriously problematic, especially in relation to blood transfusions [4]. Adjustments can be made for measured factors, but there is always the possibility of residual confounding from 'unknowns', which is more likely in complex heterogeneous populations. ICU populations are highly heterogeneous at multiple levels, including pre-illness co-morbidity, diagnosis requiring admission, early illness severity, and subsequent complications, to name a few. Dr Sakr and colleagues included adjustment for some factors but, as they acknowledge, it is very likely there were many 'unknowns' that were potentially relevant. Bias by indication is very likely in this sort of analysis whereby factors affecting a clinical decision (blood transfusion in this case) cannot be adequately captured or adjusted for, thereby introducing an imbalance. Dr Sakr and colleagues used propensity analysis in an attempt to overcome this problem, which attempts to produce matched pairs from observational data to simulate a 'virtual' randomised trial. The limitations of this approach have been previously discussed in detail in relation to another cohort study involving some of these authors [5,6]. Although the chance of erroneous associations is probably reduced, the problem remains that the patients being matched may differ in unmeasured ways. This might be more likely in a single centre study, such as the one performed by Dr Sakr and colleagues, where transfusion decision-making was presumably more consistent. The mean hemoglobin transfusion trigger was $8.2 \mathrm{~g} / \mathrm{dL}$ and in $30 \%$ of cases it was $>9 \mathrm{~g} / \mathrm{dL}$, so this ICU was significantly more liberal than the restrictive arm of the TRICC trial [3]. Another issue is that there was no information about the indications for transfusion, especially bleeding, which could have created imbalance between the matched pairs. In short, we cannot be sure of causality between blood transfusions and better outcomes, but the study does stimulate us to look again at the TRICC trial and its relevance today. 


\section{Are the findings of the TRICC trial generalisable to intensive care patients today?}

The TRICC trial found that mortality was higher in younger patients (aged $<55$ years) and those with APACHE II scores $<20$ when blood was used liberally [3]. Treatment effects were similar for older patients and those with APACHE II scores $\geq 20$, and in subgroup analyses no strong signals favouring either group were found in relation to duration of mechanical ventilation [7], or trauma diagnosis [8]. Patients with ischemic heart disease as a baseline comorbidity had a trend towards better outcome with more liberal blood use [9] and a later analysis highlighted the potential interaction between ischemic heart disease and the hemoglobin level maintained in intensive care, which could have been underestimated in the original trial report [10]. All of these subgroup analyses were underpowered, and even the full trial was much smaller than intended (the intended sample size was 1,620; achieved was 838). Another relevant factor was that clinicians declined to enrol 29\% of eligible patients. These issues raise the possibility that different treatment effects might exist for patients with ischemic heart disease, and among older and/or sicker patients, especially those with evidence of inadequate oxygen delivery or delayed weaning from mechanical ventilation. These uncertainties are acknowledged in recent guidelines and systematic reviews $[11,12]$, and it is perhaps not surprising that surveys indicate continued variation in clinical practice $[11,13]$. The other key uncertainty relates to the impact of prestorage leucodepletion, which was not used during the TRICC trial, but is now undertaken routinely in most developed countries. This additional processing step was associated with small ( $1 \%$ absolute risk reduction) but significant ICU mortality reduction in Canada, and may be particularly important with prolonged red cell storage $[14,15]$.

\section{Should we use blood more liberally in critically ill patients than the TRICC trial and our current guidelines suggest?}

The answer to this question for younger, less severely unwell patients is surely NO. For other patients we need to continue to use clinical judgement, but the evidence is still most consistent with a target haemoglobin concentration of $<9 \mathrm{~g} / \mathrm{dL}$, especially given the potential risks of blood transfusions and uncertain effectiveness of stored red cells $[11,15]$. Given our recent experiences of therapeutic strategies with early promise, but for which later trials showed conflicting safety data either overall (for example, tight glycaemic control) or in patient subgroups (for example, activated protein $\mathrm{C}$ ), it is surely time for a 'new TRICC. Only well designed randomised trials will improve our confidence in making transfusion decisions.
Unfortunately, studies such as the one performed by Dr Sakr and colleagues simply add to our uncertainty.

\section{Abbreviations}

TRICC $=$ Transfusion requirements in critical care.

\section{Competing interests}

The author declares that he has no competing interests.

Published: 23 June 2010

\section{References}

1. Sakr Y, Lobo S, Knuepfer S, Esser E, Bauer M, Settmacher U, Barz D, Reinhart K: Anemia and blood transfusion in a surgical intensive care unit. Crit Care 2010, 14:R92.

2. Marik PE, Corwin HL: Efficacy of red blood cell transfusion in the critically ill: a systematic review of the literature. Crit Care Med 2008, 36:2667-2674.

3. Hébert PC, Wells G, Blajchman MA, Marshall J, Martin C, Pagliarello G, Tweeddale M, Schweitzer I, Yetisir E: A multicenter, randomized, controlled clinical trial of transfusion requirements in critical care. N Engl J Med 1999, 340:409-417.

4. Carson JL, Reynolds RC, Klein HG: Bad bad blood? Crit Care Med 2008, 36:2707-2708.

5. Vincent JL, Sakr Y, Sprung C, Harboe S, Damas P: Are blood transfusions associated with greater mortality rates? Results of the Sepsis Occurrence in Acutely III Patients study. Anesthesiology 2008, 108:31-39.

6. Nuttall GA, Houle TT: Liars, damn liars, and propensity scores. Anesthesiology 2008, 108:3-4.

7. Hébert PC, Blajchman MA, Cook DJ, Yetisir E, Wells G, Marshall J, Schweitzer I; Transfusion Requirements in Critical Care Investigators for the Canadian Critical Care Trials Group: Do blood transfusions improve outcomes related to mechanical ventilation? Chest 2001, 119:1850-1857.

8. McIntyre L, Hebert PC, Wells G, Fergusson D, Marshall J, Yetisir E, Blajchman MJ; Canadian Critical Care Trials Group: Is a restrictive transfusion strategy safe for resuscitated and critically ill trauma patients? J Trauma 2004, 57:563-568.

9. Hébert PC, Yetisir E, Martin C, Blajchman MA, Wells G, Marshall J, Tweeddale M, Pagliarello G, Schweitzer I; Transfusion Requirements in Critical Care Investigators for the Canadian Critical Care Trials Group: Is a low transfusion threshold safe in critically ill patients with cardiovascular diseases? Crit Care Med 2001, 29:227-234.

10. Deans KJ, Minneci PC, Suffredini AF, Danner RL, Hoffman WD, Ciu X, Klein HG, Schechter AN, Banks SM, Eichacker PQ, Natanson C: Randomisation in clinical trials of titrated therapies: unintended consequences of using fixed treatment protocols. Crit Care Med 2007, 35:1509-1516.

11. Napolitano LM, Kurek S, Luchette FA, Corwin HL, Barie PS, Tisherman SA Hebert PC, Anderson GL, Bard MR, Bromberg W, Chiu WC, Cipolle MD, Clancy KD, Diebel L, Hoff WS, Hughes KM, Munshi I, Nayduch D, Sandhu R, Yelon JA; American College of Critical Care Medicine of the Society of Critical Care Medicine; Eastern Association for the Surgery of Trauma Practice Management Workgroup: Clinical practice guideline: red blood cell transfusion in adult trauma and critical care. Crit Care Med 2009, 37:3124-3157

12. Hill SR, Carless PA, Henry DA, Carson JL, Hebert PC, Henderson KM: Transfusion thresholds and other strategies for guiding allogeneic red blood cell transfusion. Cochrane Database Syst Rev 2002:CD002042.

13. Walsh TS, Maciver CR: A clinical scenario-based survey of transfusion decisions for intensive care patients with delayed weaning from mechanical ventilation. Transfusion 2009, 49:2661-2667.

14. Hébert PC, Fergusson D, Blajchman MA, Wells GA, Kmetic A, Coyle D, Heddle N, Germain M, Goldman M, Toye B, Schweitzer I, vanWalraven C, Devine D, Sher GD; Leukoreduction Study Investigators: Clinical outcomes following institution of the Canadian universal leukoreduction program for red blood cell transfusions. JAMA 2003, 289:1941-1949.

15. Zimrin $A B$, Hess JR: Current issues relating to the transfusion of stored red blood cells. Vox Sanguinis 2009, 96:93-103.

doi:10.1186/cc9043

Cite this article as: Walsh TS: Red cell transfusion triggers in critically ill patients: time for some new TRICCs? Critical Care 2010, 14:170. 